\title{
Knowledge and Awareness of Masks and N95 Respirators Used for COVID-19 Prevention Among Chemical Engineering Students at Al-Balqa Applied University, Jordan
}

\author{
Banan Hudaib $^{1 *}$, Ali F. Al-shawabkeh ${ }^{2}$ and Fadia Hudaib ${ }^{3}$ \\ ${ }^{1}$ Chemical Engineering Department, Faculty of Engineering Technology, Al-Balqa Applied University, Amman, Jordan, \\ ${ }^{2}$ Physics and Basic Sciences Department, Faculty of Engineering Technology, Al-Balqa Applied University, Amman, Jordan, \\ ${ }^{3}$ Amman College of Banking and Financial Studies, Al-Balqa Applied University, Amman, Jordan
}

OPEN ACCESS

Edited by:

Amin Talebi Bezmin Abadi, Tarbiat Modares University, Iran

Reviewed by:

Enahoro Iboi,

Spelman College, United States

Minh Cuong Duong,

University of New South

Wales, Australia

Mohamad Y. Fares,

University of Glasgow,

United Kingdom

*Correspondence:

Banan Hudaib

banan.hudaib@bau.edu.jo

Specialty section:

This article was submitted to

Public Health Education and

Promotion,

a section of the journal

Frontiers in Public Health

Received: 23 October 2020 Accepted: 01 December 2021

Published: 07 January 2022

Citation:

Hudaib B, Al-shawabkeh AF and Hudaib $F$ (2022) Knowledge and

Awareness of Masks and N95

Respirators Used for COVID-19

Prevention Among Chemical Engineering Students at Al-Balqa

Applied University, Jordan

Front. Public Health 9:620725.

doi: 10.3389/fpubh.2021.620725
Background and Objectives: On March 11, the World Health Organization stated coronavirus disease 2019 (COVID-19) was a global pandemic; the rapid and extended spread of the COVID-19 pandemic has become a significant cause of concern for face-to-face university study. This study investigated the knowledge and awareness of chemical engineering students in Al-Balqa Applied University (BAU) in Jordan about respiratory protective measures against COVID-19.

Materials and Methods: A cross-sectional study was developed using a multi-stage random sampling technique conducted from April 21-28, 2020. The data were collected through an online questionnaire distributed to BAU's chemical engineering students, with 179 responders completed the survey correctly. The data were analyzed statistically using the SPSS program. The questionnaire consisted of two parts: the first measured the student's general knowledge about the COVID-19 pandemic, while the second focused on the respiratory protection methods against COVID-19; it was structured to assess the student's knowledge about the suitable types of masks and respirators used in COVID-19 prevention, their detailed mechanism of action and filtration process type, their production materials, and finally how the student's knowledge affects choosing a proper preventive method.

Results: The study found moderate awareness among engineering students about COVID-19 causative agent, effective preventive masks/respirators used, and the mask's viral blockage mechanisms. A total of 89 respondents $(49.7 \%)$ pointed to the correct best protective mask, i.e., N95 mask. On the other hand, 119 respondents (66.5\%) believed that a surgical mask is the best protective mask. The study also showed differences in knowledge between different academic years; the knowledge about respirators, masks, and their action mechanism among senior students in the last three academic years was better than the younger students with a $P$-value of 0.047 for knowledge about respirator used for protection against coronavirus disease and the $P$-value of 0.028 for knowledge of the comparisons between the N95 and surgical mask. On the other hand, the study showed a lack of awareness of the most suitable mask types used in pandemics and the appropriate use method. 
Conclusions: The study found that chemical engineering students in Al-Balqa university were moderately knowledgeable regarding COVID-19 respiratory preventive methods; these results provided an overview of each student's community's knowledge level. Therefore, efforts are needed to improve public awareness through comprehensive educational campaigns to increase students' knowledge, attitude, and practice.

Keywords: COVID-19, masks and respirators, chemical engineering students, Jordan, Al-Balqa Applied University

\section{INTRODUCTION}

Infectious diseases are considered to be the second leading cause of death worldwide (1). Among infectious diseases causing death worldwide, acute lower respiratory tract infections, HIV/AIDS, and diarrheal diseases predominated $(2,3)$.

In late December 2019, multiple influenza and severe pneumonia cases spread quickly in Wuhan, China, and a new species of the coronavirus family was responsible for the new zoonotic disease (4). Initially, the World Health Organization (WHO) named the causative virus as 2019 novel coronavirus (2019-nCOV), and then the name was updated later to SARSCOV-2 (5), and the disease was named coronavirus disease 2019 (COVID-19) (6, 7). On March 11, 2020, WHO declared COVID19 as a global pandemic, and the new disease started to spread worldwide in many countries, including Jordan (8).

COVID-19 is a respiratory syndrome, and it is of paramount importance to determine the route of transmission of the infectious agent (e.g., directly via respiratory droplets/airborne or indirectly through contaminated, infected surfaces) to build a suitable strategy to cope with a pandemic which will be based solely on this knowledge and upon the preventive tools available (9).

The primary disease spread prevention strategies in a new influenza pandemic rely solely on non-pharmacological primary public health measures as a part of a larger strategy to establish barriers and increase distancing between infected and uninfected individuals (10), as the lack of the effective vaccine and antiviral medications and the long time required to develop them make these the available defense measures (11).

The awareness of the importance of respiratory barriers in preventing respiratory disease transmission, knowledge of the general differences between the different types of respirators and masks used in the COVID-19 pandemic, and the type of filter (membrane) used in these masks had a significant influence on the personal attitude toward the use of these barriers (12). Masks are routinely and obligatorily used by chemical engineers in the work environment to deal with different chemicals and gases. Chemical engineering students are studying membranes, filtration, and separation processes topics during the Bachelor of Science curriculum starting from the third year.

Therefore, our study aimed to assess knowledge and awareness among our chemical engineering students regarding the types of respirators, mask, and the significant differences between various types, as well as to measure the extent of their knowledge about the filtration mechanism and the impact of the student's knowledge on the choice of the appropriate mask to prevent COVID-19. In addition, the study aimed to assess the knowledge effect on understanding the best preventive measures of pandemic transmission and explore the differences in knowledge between junior and senior students.

\section{THEORETICAL BACKGROUND AND LITERATURE REVIEW}

COVID-19 virus, which belongs to a big family of coronaviruses that causes different infectious diseases, is the most recently discovered coronavirus family member. The new virus was unknown before the outbreak started in Wuhan, China, in December 2019. However, the enormous and rapid outbreak of COVID-19 affected most world countries leading to the WHO declaration of COVID-19 as a global pandemic.

COVID-19 spread mainly from an infected person to others by breathing the expelled tiny droplets from the nose or mouth during coughing, sneezing, or speaking. Those droplets are relatively heavy and quickly dropped to the ground's surface; thus, people can become infected by touching these objects or surfaces. Therefore, wearing masks, wearing gloves, and washing hands regularly are the primary protection methods $(13,14)$.

According to the WHO, there are three main types of masks used to protect against the spread of COVID-19. Those are (15):

1. Medical masks or surgical masks made from a minimum of three layers of synthetic non-woven materials and configured to have filtration layers sandwiched in the middle.

2. Non-medical masks (fabric masks, homemade masks, DIY masks) act as a barrier to prevent virus spread from the wearer to the public. Numerous types of fabric masks are not standardized, and other preventive measures should be taken.

3. Respirators, or filtering face-piece respirators (FFP), are specifically designed for healthcare workers (HCWs) providing care to COVID-19 patients in hospitals and areas where aerosol-generating procedures are performed. These respirators are available at different performance levels, such as FFP2, FFP3, N95, and N99. Healthcare workers should be fit tested before using a respirator to ensure they are wearing the correct size (16).

Alzoubi et al. (6) evaluated the COVID-19 knowledge, practice, and attitude among Jordan's medical and non-medical university students. The study's findings showed a positive response regarding the overall knowledge about the symptoms of COVID19. All students agreed that hand washing is necessary to prevent infection, whereas $68.4 \%$ believed that masks prevent the 
infection. One-fifth of them thought that antibiotics and smoking were protective measures against infection. Concerning avoiding handshaking, washing hands, using alcoholic hand sanitizer, coughing, or sneezing in tissue and disposing of it, almost all students agreed on these preventive practices. In this study, social media, the internet, and television were the primary sources of students' knowledge about COVID-19. The results showed no significant differences in knowledge between medical and non-medical students.

Modi et al. (11) studied COVID-19 awareness among healthcare students and professionals in Mumbai metropolitan region and found that the overall awareness for all subgroups was adequate. A total of $71.2 \%$ of respondents reported correct answers in the Mumbai metropolitan region. Undergraduate medical students gave the highest percentage of correct responses, while the lowest was the non-clinical administrative staff. The results showed that less than half of the total respondents correctly defined "close contact." At the same time, more than three-fourths of the respondents were aware of the various infection control measures like rapid triage, respiratory hygiene, cough etiquette, and having a separate, well-ventilated waiting area for suspected COVID-19 patients. Nevertheless, only $45.4 \%$ of the respondents knew the correct sequence for applying a mask/respirator, and only $52.5 \%$ of the respondents were aware of the preferred hand hygiene method for visibly soiled hands.

Kumar et al. (7) investigated HCW's knowledge, attitude, and practices regarding using face masks for COVID-19 prevention. They found that $43.6 \%$ of participating HCWs in Pakistan knew the correct method of wearing the masks, $70 \%$ knew the number of layers, $53 \%$ stated that the middle layer acts as a filter media barrier, and more than three-fourths knew the recommended maximum wearing duration. The results also showed that the majority, $88.2 \%$, of participants knew that a cloth face mask is less effective, and $79.8 \%$ knew that worn face masks should not be re-used, while $44.8 \%$ knew about the yellow coded bag for disposal. Although the study concluded that the knowledge, attitude, and practice of HCWs regarding the use of face masks were inadequate, it was noticed that there is a positive attitude, but a moderate-to-poor level of knowledge practice, regarding face masks use among HCWs. The study recommended that awareness campaigns for HCWs and the general public regarding the proper use of face masks utilizing all social media resources can help.

Iboi et al. (12) investigated the rule of effective public health education measures in minimizing both the cumulative and daily mortality of the COVID-19 in the United States. The results indicated that more coronavirus cases were experienced in places with a reduced commitment to public health measures, and the daily mortality was increased compared to places with strict commitment. Similar results were obtained by other studies $(10,17)$, where the universal use of face masks significantly reduced community transmission of COVID-19 and brought the pandemic under effective control. This highlights the importance of knowledge about mask types, appropriate mask selection, and the protection mechanism of the most suitable masks against COVID-19.
Iboi et al. (12) carried out a modeling study to determine the influence of public health education programs on the US coronavirus outbreak. The model used cumulative mortality data for the United States from January to December 2020. According to the study, a $10 \%$ increase in education rate from the baseline reduces the peak daily mortality by $66.3,26.7$, and $16 \%$ by April, July, and December, respectively, compared to a baseline scenario. However, a $40 \%$ increase in education from the baseline reduces the peak daily mortality by $96.8,44.5$, and $54.8 \%$ by April, July, and December, respectively. This demonstrated improved public education and the universal use of face masks curtailed COVID-19 transmission and effectively affected the pandemic.

\section{The COVID-19 Outbreak Worldwide and in Jordan}

According to the last statistics of the Worldometer website, a total of 237,826,700 registered cases infected with COVID-19 $(214,870,766)$ recovered, and the virus caused the death of about $4,853,179$, representing about $2 \%$ of the closed cases (18).

In Jordan, 831,832 infected cases were registered with 10,789 deaths, and 807,569 cases recovered.

Figure 3 shows the trends of the new and accumulated cases globally and in Jordan.

\section{Using Masks in the Context of COVID-19 Worldwide}

One observational study showed that using face masks was $79 \%$ effective in preventing COVID-19 transmission if all members applied them before symptoms appeared (19). A survey done by Ipsos group (20). in April 2020 showed that among people across 15 major countries, the highest percentage of people who wore masks were in Vietnam (91\%), China (83\%), Italy (81\%), Japan (77\%), and India (76\%), and the high percentage in Vietnam was attributed to the high percentage of survey respondents who believed that people should wear masks in public to protect others (21). Figures 1, 2 shows the mask user's percentage in Jordan and worldwide, respectively. Figure 2 illustrates that $24 \%$ of Jordan's population said they always wear a mask in public compared to the universal target, which is $95 \%$. However, compared to other countries worldwide, Figure 3 indicated that the population who used masks is $<54 \%$ in most countries, including the United States, Europe, and Russia. In contrast, the highest percentage was in Mexico, the western countries of South America, Saudi Arabia, and South Africa countries, in which the percentage exceeded $74 \%$ of the total population.

\section{METHODOLOGY}

A cross-sectional study was conducted using a multi-stage random sampling technique from April 21-28, 2020. The data were collected through an online questionnaire distributed to the chemical engineering students of Al-Balqa Applied University (BAU). The target population for this study is 400 students enrolled in the BAU chemical engineering department in Amman. The questionnaire was distributed to the students 


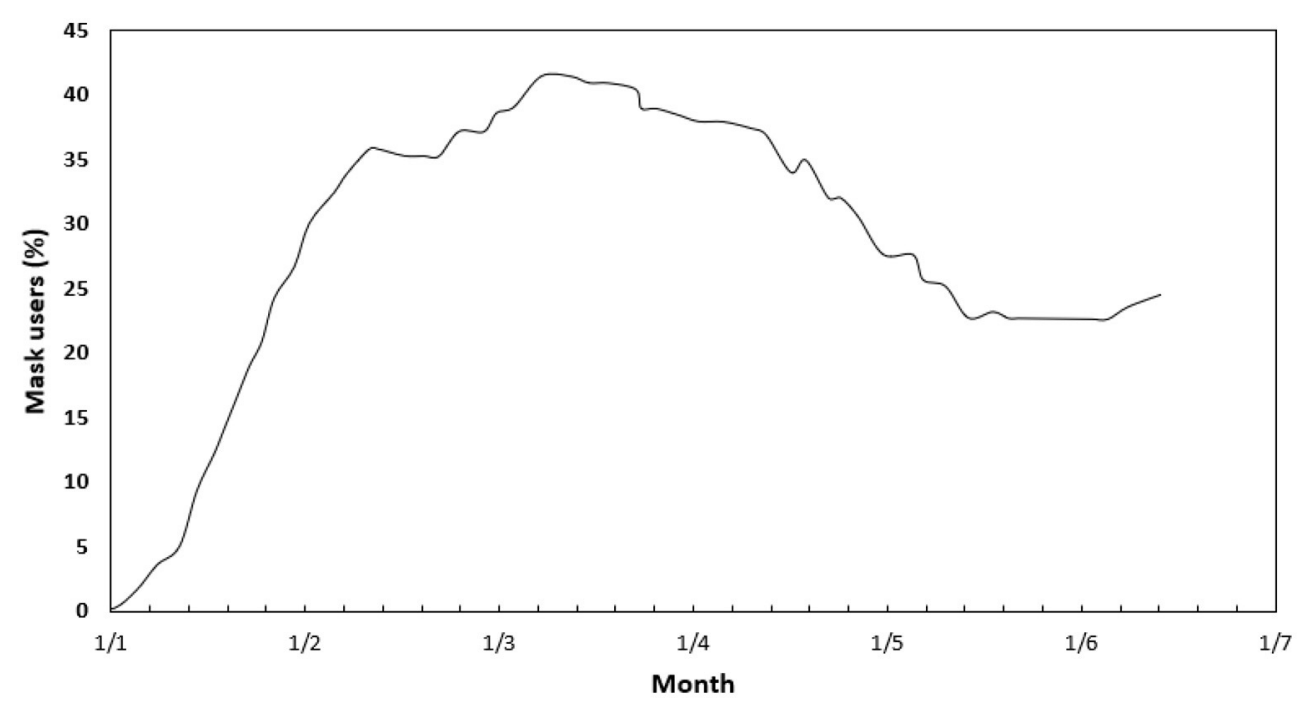

FIGURE 1 | The projected masks users percentage in Jordan.

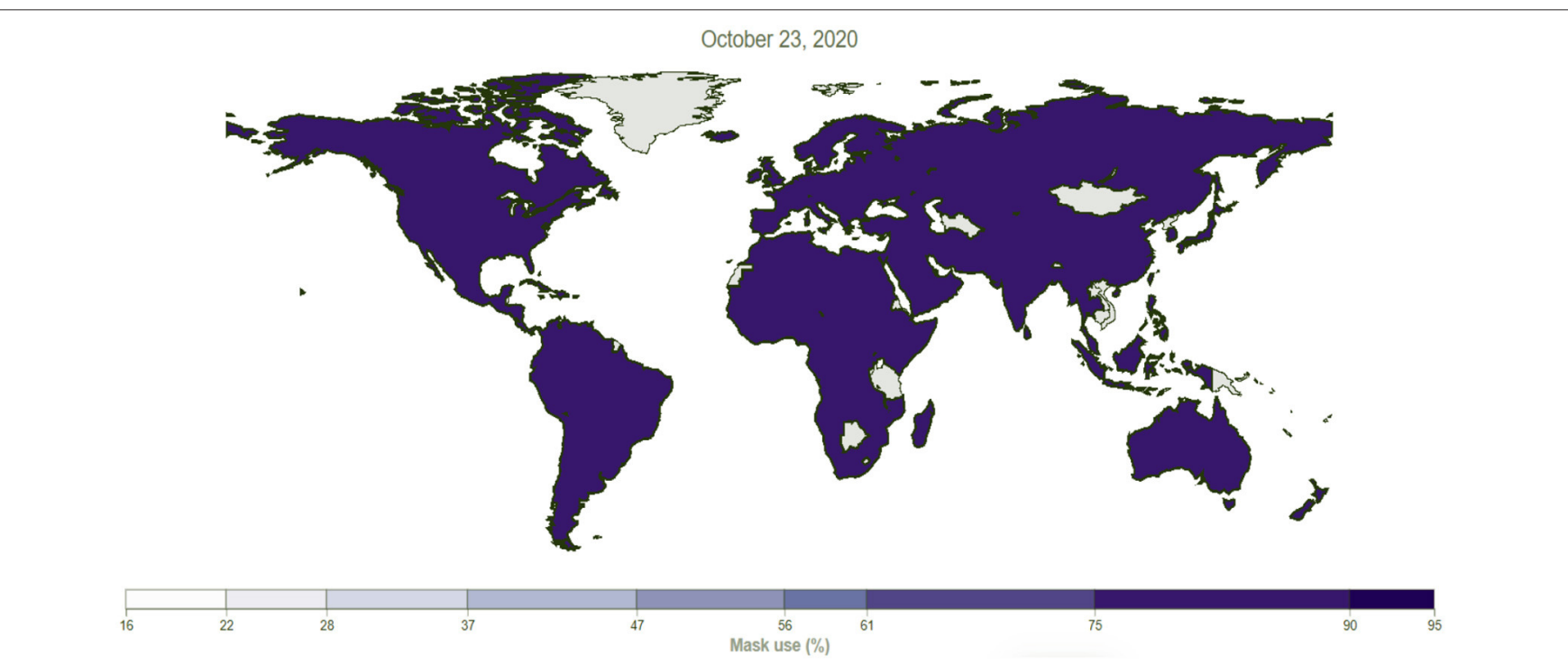

FIGURE 2 | The percentage of mask users of the population in the world. Data sources: https://covid19.healthdata.org/jordan?view=mask-useandtab=trend, (22, 28).

through the internet (department Facebook groups). Out of 400 enrolled students in the department, 179 responders completed the survey correctly, the author received 200 responses and excluded 15 incomplete responses and six responses filled by non-chemical engineering students. The data were analyzed statistically using the SPSS software. The online developed questionnaire consisted of a 20-paragraph/multiplechoice designed in two parts to fulfill the study objectives. The first part is about the respondent's demographic characteristics (age, level, gender). The second part measured the respondent's knowledge about COVID-19, transmission and prevention methods, and the quality of masks and respirators used. Moreover, a two tail $T$-test was used to explore whether any statistical difference existed in the respirator knowledge between students of the first 2 years (group 1) and the last three academic years (group 2) using SPSS for the analysis.

The validity of research findings was ensured through expert consultations with lecturers from BAU. According to Borg and Gall (23), the content validity of an instrument is improved through expert judgment. To enhance the reliability of the study findings, piloting of the questionnaires was conducted among selected chemical engineering students in BAU. The piloting sample size was selected on a proportion of $10 \%$ of the study sample size and then the reliability of the study instruments was calculated using Cronbach's Coefficient Alpha. According to Fraenkel and Wallen (24), a reliability coefficient of 0.7 and above 

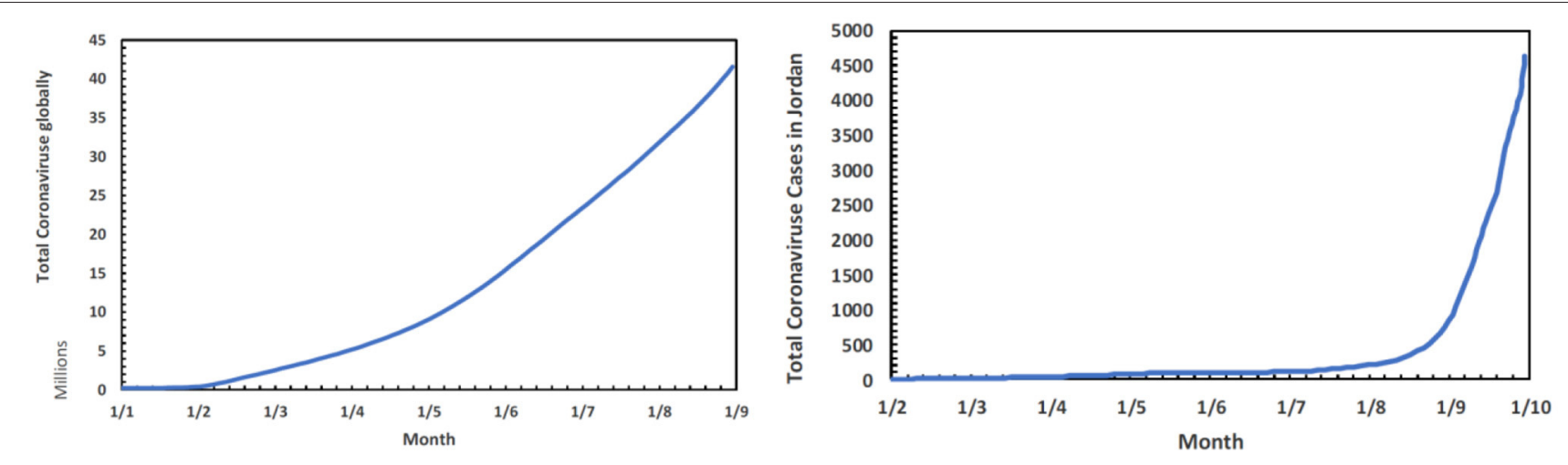

FIGURE 3 | Trends of the new and accumulated cases globally and in Jordan.

TABLE 1 | The demographic characteristic of the study sample.

\begin{tabular}{llcc}
\hline Variable & & Frequency & Percentage \\
\hline Gender & Female & 103 & 57.5 \\
& Male & 76 & 42.5 \\
Age & $18-25$ & 164 & 91.6 \\
& $26-30$ & 10 & 5.6 \\
& $31-35$ & 5 & 2.8 \\
Academic year: & Fresh (1st year) & 8 & 4.5 \\
& Sophomore (2nd year) & 59 & 33.0 \\
& Junior (3rd year) & 16 & 8.9 \\
& Seniors (4th year) & 54 & 30.2 \\
Total respondents & Super Senior (5th year) & 42 & 23.5 \\
& & 179 & 100.0 \\
\hline
\end{tabular}

implies that the study instruments are reliable; thus, this criterion was used to assure the reliability of the study instruments.

\section{RESULTS AND DISCUSSIONS \\ Source of Information About COVID-19 Among Students}

Table 1 shows the demographic characteristic of the respondents.

Out of 400 enrolled students in the department, 179 respondants $(44.7 \%)$ completed the survey correctly; the author received 200 responses and excluded 15 incomplete responses and six responses sent by non-chemical engineering students. The female respondants in the study sample were 103 (57.5\%), and the rest were males. Most of the respondents were between 18-25 years old. Fifty-nine students (33\%) were second-year level, 54 (30.2\%) and 42 students (23.5\%) were fourth- and fifthyear levels, while first- and third-year level students made only $8(4.5 \%)$ and 16 students (8.9\%), respectively. As there is an optional course for membrane and separation processes offered to $3 \mathrm{rd}, 4 \mathrm{th}$, and 5 th-year students, most of the respondents from this academic level are expected to be familiar with different types
TABLE 2 | Sources of Knowledge about COVID-19 outbreak.

\begin{tabular}{lc}
\hline Method & Percentage \\
\hline Social media & 99.4 \\
TV/radio & 62.6 \\
Poster and brochures & 17.3 \\
Friends and colleagues & 36.3 \\
Seminars & 20.1 \\
One method & 22.9 \\
Two methods & 43 \\
Three methods & 10.1 \\
Four methods & 14.5 \\
Five methods & 7.3 \\
& 100.0
\end{tabular}

of masks, their mechanism of action, and their appropriate use, and this knowledge would help to answer the questionnaire.

Table 2 showed that social media was the primary source of information about COVID-19; 178 students (99.4\%) knew about the pandemic from social media as a single source or in addition to other sources. TV/Radio was the second source of information with 111 students $(62.3 \%)$, followed by 65 students (36.3\%) knew from friends and colleagues. Also, 31 students (17.3\%) mentioned that the source of information about COVID19 was posters/brochures and 36 students (20.3\%) learned about COVID-19 from seminars.

Forty-one students (22.9\%) mentioned social media as the only source of information about COVID-19, which points to the importance of social media as an essential source of information in the COVID-19 pandemic.

\section{Knowledge About the Disease}

Knowledge about the disease is fundamental for protecting ourselves and making the most effective measures to prevent the disease.

Most of the respondents thought that COVID-19 is a serious public health problem; however, only 38 students 
(21.2\%) correctly named the causative agent, i.e., the SARSCov-2 virus. It is well-known that contact with an infected person is the primary source of infection of COVID-19 either through breathing the droplets from the nose or mouth expelled when the infected person coughs, sneezes, or speaks from a distance $<1 \mathrm{~m}$, or through touching contaminated surfaces (25). A total of 126 respondents (70.4\%) pointed to those two methods of COVID-19 transmission in addition to one or more other methods. However, 185 respondents (88.3\%) mentioned contact with an infected person besides other methods, and $146(81.6 \%)$ mentioned touching contaminated surfaces besides other methods.

The previous results strongly indicated an excellent general knowledge among students regarding disease transmission methods.

Table 3 shows that most of the respondents mentioned more than one method of virus prevention. A total of 112 respondents (62.6\%) mentioned masks and 121 respondents $(67.8 \%)$ mentioned face shields, and 68 respondents (38\%) chose both of them as an efficient method of preventing disease besides other methods, which indicates the respondents' awareness of mask and face shield importance in preventing COVID-19 infection.

Most respondents stated that using masks, wearing gloves, and washing hands prevents the disease's transmission effectively.

\section{Quality of Protection Masks}

Table 4 shows students' responses regarding the details of the masks used to protect against COVID-19. The table indicates that 85 respondents $(47.5 \%)$ knew the filter type and understood its action mechanism and how it affected the selection of the mask type; this may be attributed to their academic background and familiarity with masks in the lab. However, the respondents who answered with no idea are very high for most of those questions.

Table 4 showed that 89 respondents $(49.7 \%)$ chose the correct best protective mask, i.e., N95 mask $(10,16)$. In contrast, about two-thirds of the respondents believed that the surgical mask was the best protective mask. In addition, 104 students (58.1\%) mentioned the scarf, and 79 students $(44.1 \%)$ had no idea about the correct type of mask that should be used.

Moreover, 92 respondents $(51.4 \%)$ pointed to non-woven fabrics as the correct material used in masks/respirators production. Only 35 respondents (19.6\%) knew the correct membrane filtration process used in masks (26). A total of 62 respondents $(34.7 \%)$ stated that the mask should be disposed of after a single use.

A total of 37 students (20.7\%) mentioned that the mechanisms by which the masks/respirators can block viruses are interception, while 55 students (30.7\%) chose inertial blockage, and 47 students $(26.3 \%)$ chose diffusion (27).

Table 4 shows that 66 students (36.9\%) stated that the factor affecting filtration process in respirators and masks is the mechanism of filtration, while 32 students(18.4\%) chose the number of mask layers and 35 students $(20.1 \%)$ chose the type of polymers used, while the size of the filtered material was chosen by 47 students $(26.3 \%)$ (28).
TABLE 3 | The attitudes of the respondents about COVID-19 knowledge about protective mask used in COVID-19.

\begin{tabular}{|c|c|c|}
\hline & & Percentage \\
\hline The risk of COVID-19 & $\begin{array}{l}\text { Serious public health } \\
\text { problem }\end{array}$ & 95.5 \\
\hline \multirow{6}{*}{$\begin{array}{l}\text { Coronavirus disease } \\
\text { COVID-19 is caused by }\end{array}$} & MERS-CoV & 2.2 \\
\hline & & \\
\hline & Bacteria from bats & 16.8 \\
\hline & MERS-CoV & 8.4 \\
\hline & SARS-COV2 & 21.2 \\
\hline & No idea & 51.4 \\
\hline \multirow{7}{*}{$\begin{array}{l}\text { Coronavirus disease } \\
\text { (COVID-19) is } \\
\text { transmitted by }\end{array}$} & Coughing and sneezing & 82.1 \\
\hline & Air & 34.6 \\
\hline & Handshaking & 65.9 \\
\hline & $\begin{array}{l}\text { Contact with an infected } \\
\text { person }\end{array}$ & 88.3 \\
\hline & $\begin{array}{l}\text { Touching contaminated } \\
\text { surfaces }\end{array}$ & 81.6 \\
\hline & Food & 44.7 \\
\hline & $\begin{array}{l}\text { Contact with an infected } \\
\text { person and Touching } \\
\text { contaminated surfaces }\end{array}$ & 70.4 \\
\hline \multirow{9}{*}{$\begin{array}{l}\text { Coronavirus disease } \\
\text { (COVID-19) can be } \\
\text { prevented by }\end{array}$} & Avoiding crowds & 81.3 \\
\hline & Social distancing & 61.5 \\
\hline & Gloves & 77.1 \\
\hline & Masks & 62.6 \\
\hline & Face shield & 67.8 \\
\hline & Both masks and shield & 38.0 \\
\hline & Avoiding traveling & 78.2 \\
\hline & Staying home & 78.8 \\
\hline & More than one & 96.1 \\
\hline
\end{tabular}

Although the study population presumed to have good academic background regarding membranes and filtration processes, the results showed that this academic background is inadequate, with only half of the respondents knowing the correct mask type and its blockage mechanism.

Table 5 reflected students' understanding of differences between various protective masks; more than half of the respondents realized that surgical masks are a more practical choice in the COVID-19 pandemic than N95. However, only two students (1\%) knew that N95 masks are more efficient than surgical masks, and 27 students (15\%) knew that the N95 mask was named after a blockage of (95\%) of aerosols particles.

\section{The Authority Responsible for Testing and Approval of N95/P95 Respirators}

Table 6 indicates that 101 respondents (56.4\%) agreed that National Institute for Occupational Safety and Health (NIOSH) is the authority responsible for testing and approval of N95/P95 masks (16). National Institute for Occupational Safety and 
TABLE 4 | Knowledge about the respirators used for protection against Coronavirus disease (COVID-19).

\begin{tabular}{|c|c|c|}
\hline $\begin{array}{l}\text { Understanding of filter type } \\
\text { and mechanism affect our } \\
\text { attitude in the selection of } \\
\text { the mask type }\end{array}$ & Yes & 47.5 \\
\hline \multirow[t]{5}{*}{ Types of masks/respirators } & Surgical mask & 66.5 \\
\hline & N95 mask & 49.7 \\
\hline & P95 mask & 29.6 \\
\hline & Scarf & 58.1 \\
\hline & No idea & 44.1 \\
\hline Material for membranes & Non-woven fabrics & 51.4 \\
\hline used in the filter of & Silk & 6.1 \\
\hline \multirow[t]{2}{*}{ masks/respirators } & Wool & 3.9 \\
\hline & No idea & 38.5 \\
\hline \multirow[t]{4}{*}{$\begin{array}{l}\text { Type of the membrane } \\
\text { filtration }\end{array}$} & $\begin{array}{l}\text { Between ultrafiltration and } \\
\text { microfiltration }\end{array}$ & 19.6 \\
\hline & reverse osmosis & 6.7 \\
\hline & $\begin{array}{l}\text { Between reverse osmosis } \\
\text { and nanofiltration }\end{array}$ & 17.3 \\
\hline & No idea & 56.4 \\
\hline In using respirators/surgical & Sterilize & 24.0 \\
\hline masks. It is recommended & Avoid wearing mask & 7.3 \\
\hline \multirow[t]{3}{*}{ to: } & Dispose of after use & 34.6 \\
\hline & Use it continuously & 12.8 \\
\hline & No idea & 31.3 \\
\hline The mechanisms in which & Interception of the virus & 20.7 \\
\hline the masks/respirators block & $\begin{array}{l}\text { Inertial blockage of the } \\
\text { virus }\end{array}$ & 30.7 \\
\hline \multirow[t]{3}{*}{ viruses } & Diffusion & 26.3 \\
\hline & Electrostatic & 5.6 \\
\hline & No idea & 45.3 \\
\hline The filtration process in & Mechanism & 36.9 \\
\hline respirators and masks & Number of mask layers & 18.4 \\
\hline \multirow[t]{3}{*}{ depends on } & Type of polymers used & 20.1 \\
\hline & Size of the filtered & 26.3 \\
\hline & No idea & 39.7 \\
\hline
\end{tabular}

Health, a part of the U.S. Centers for Disease Control and Prevention, certifies filtering face-piece N95 respirators that meet the criteria for a minimum 95 filter efficiency at the most penetrating particle size. While unfortunately, most respondents were not aware of the authority responsible for surgical masks testing, only seven students (3.9\%) knew that Food and Drug Administration (FDA) is responsible for testing and approving surgical masks (16).

Table 7 demonstrates the statistical comparison between students of the first 2 years (group 1) and the last three academic years (group 2) using SPSS, two tail $T$-test regarding knowledge and sources of knowledge about COVID-19, the respondent's attitudes about COVID-19, knowledge about the respirators used for protection against COVID-19, and comparison between the N95 and surgical masks. The p-values of knowledge, sources of knowledge and attitude toward COVID-19, knowledge about the respirators, and N95/surgical masks comparison were $0.345,0.317,0.047$, and 0.028 , respectively. According to two
TABLE 5 | Comparison between the N95 and surgical masks.

\begin{tabular}{lll}
\hline $\begin{array}{l}\text { Regarding the } \\
\text { differences between } \\
\text { surgical masks and } \\
\text { respirators (N95) }\end{array}$ & $\begin{array}{l}\text { N95 is used to reduce the } \\
\text { risk of inhaling hazardous } \\
\text { airborne particles }\end{array}$ & 35.2 \\
& $\begin{array}{l}\text { Surgical masks are designed to } \\
\text { be used by an infected person, } \\
\text { healthcare worker, or member } \\
\text { of the public to reduce the } \\
\text { transfer of body fluids that may }\end{array}$ & \\
spread infection \\
Both are the same \\
N95 are more efficient than \\
surgical masks \\
Surgical masks are a more \\
practical choice in pandemic \\
Block 5\% of the aerosol's \\
particles \\
Used for an oil-free atmosphere \\
Block 95\% of the aerosol's \\
particles \\
Collect all particle size >95\% \\
No idea
\end{tabular}

TABLE 6 | Authority responsible for testing and approval of N95/P95 respirators.

\begin{tabular}{lcc}
\hline Organization & N95/P95 & Surgical masks \\
\hline FDA & 19.6 & 3.9 \\
WHO & 6.7 & 25.1 \\
NIOSH & 56.4 & 20.1 \\
NO IDEA & 17.3 & 50.8 \\
& 100.0 & 100.0
\end{tabular}

tailed-values (as the $p$-value $>0.05$ ) there were no significant statistical differences between the students regarding knowledge, source of knowledge, and attitude toward COVID-19 based on their academic year; these results are expected due to globalwide coverage of disease facts in social media and the strict measures imposed by the governments immediately after its announcement as a pandemic by WHO.

There were significant statistical differences between the two groups regarding knowledge about the respirators used for protection against COVID-19 and the differences between N95 and surgical masks, with $P$-value $<0.05$. These results could be explained, as group 2 (senior students) have finished many topics related to the separation processes in their college curriculum.

\section{Limitations of the Study}

The limitations of this study could include a low response rate and small sample size, which could be due to lockdown during the survey distribution time and sampling-related issues like the inability to verify the respondent's identity. However, the questionnaire can be extended to include the entire engineering students at Al-Balqa University and several universities in Jordan to investigate the knowledge trends among engineering students in Jordan. This survey was done in the early time of 
TABLE 7 | Independent Samples Test, regarding the mean difference of knowledge and source of knowledge, attitude, knowledge about the respirators and comparison between the N95 and surgical masks level between chemical engineering students of the first three academic years and the last two academic years.

\begin{tabular}{lcccc}
\hline & $\boldsymbol{T}$ & $\boldsymbol{d f}$ & $\begin{array}{c}\text { Sig } \\
\text { (2-tailed) }\end{array}$ & $\begin{array}{c}\text { Mean } \\
\text { difference }\end{array}$ \\
\hline $\begin{array}{l}\text { Knowledge and sources of } \\
\text { knowledge about } \\
\text { coronavirus disease } \\
\text { (COVID-19) outbreak }\end{array}$ & -0.686 & 112 & 0.345 & -0.008 \\
$\begin{array}{l}\text { The attitudes of the } \\
\text { respondents about the } \\
\text { coronavirus disease }\end{array}$ & -0.611 & 112 & 0.317 & -0.002 \\
$\begin{array}{l}\text { Knowledge about the } \\
\text { respirators used for } \\
\text { protection against } \\
\text { coronavirus disease } \\
\text { (COVID-19) }\end{array}$ & -1.516 & 175 & 0.047 & -0.017 \\
$\begin{array}{l}\text { Comparison between the } \\
\text { N95 and surgical masks }\end{array}$ & -1.591 & 175 & 0.028 & -0.022 \\
\hline
\end{tabular}

COVID-19. This could be added to limitations as the strategy and knowledge regarding COVID-19 were still growing among the public worldwide. Hence, the results would be different 1 year later.

\section{CONCLUSION}

This study showed moderate awareness of engineering students in BAU-Jordan about masks used in COVID-19 prevention.

\section{REFERENCES}

1. WHO. World Health Organization Report-Health Systems: Improving Performance. Geneva: World Health Organization (2000).

2. Mandi H, Epie BC, Eyoh A, Jan S, Clemens SAC, Clemens R, et al. Seroepidemiology of respiratory syncytial virus infection in rural and semirural areas of the littoral region of Cameroon. BMC Infect Dis. (2021) 21:144. doi: 10.1186/s12879-021-05838-w

3. Levine MM, Nasrin D, Acácio S, Bassat Q, Powell H, Tennant SM, et al. Diarrhoeal disease and subsequent risk of death in infants and children residing in low-income and middle-income countries: analysis of the gems case-control study and 12-month GEMS-1A follow-on study. Lancet Global Health. (2020) 8:e204-14. doi: 10.1016/S2214-109X(19)3 0541-8

4. Li H, Liu S, Yu X, Tang S, Tang C. Coronavirus disease 2019 (COVID19): current status and future perspectives. Int J Antimicrob Agents. (2020) 55:105951. doi: 10.1016/j.ijantimicag.2020.105951

5. Rabaan AA, Al-ahmed SH, Haque S, Sah R, Tiwari R. SARS-CoV-2, SARSCoV, and MERS-CoV: a comparative overview. Infez Med. (2020) 28:174-84.

6. Alzoubi H, Alnawaiseh N, Al-Mnayyis A, Abu-Lubad M, Aqel A, Al-Shagahin H. COVID-19 - knowledge, attitude and practice among medical and nonmedical university students in Jordan. J Pure Appl Microbiol. (2020) 14:1724. doi: 10.22207/JPAM.14.1.04

7. Kumar J, Katto MS, Siddiqui AA, Sahito B, Jamil M, Rasheed N, et al. Knowledge, attitude, and practices of healthcare workers regarding the use of face mask to limit the spread of the new coronavirus disease (COVID-19). Cureus. (2020). 12:e7737. doi: 10.7759/cureus.7737
Keeping in mind the students' academic background regarding membranes and separation process, it is evident that the knowledge of membrane type and filtration process and blockage mechanism was inadequate, adversely affecting students' choice of suitable preventive masks. Therefore, it is recommended to increase the number of academic courses focusing on membranes and filtration processes; this will help raise knowledge and awareness and engage students positively in changing community COVID-19 prevention attitude.

\section{DATA AVAILABILITY STATEMENT}

The raw data supporting the conclusions of this article will be made available by the authors, without undue reservation.

\section{ETHICS STATEMENT}

Ethical review and approval was not required for the study on human participants in accordance with the local legislation and institutional requirements. Written informed consent for participation was not required for this study in accordance with the national legislation and the institutional requirements.

\section{AUTHOR CONTRIBUTIONS}

BH prepared the survey and collected the data. AA-s and FH contributed to statistical analysis of the data. BH, AA-s, and $\mathrm{FH}$ authors involved in the discussion of the results. All authors contributed to the article and approved the submitted version.

8. WHO Audio Conference. WHO Audio Emergencies Coronavirus Press Conference Full and Final - Vol. 11. (2020), 1-9. Available online at: https:// www.who.int/director-general/speeches/detail/who-director-general-sopening-remarks-at-the-media-briefing-on-covid-19-\$-\$11-march-2020 (accessed March 11, 2020).

9. Li Q, Guan X, Wu P, Wang X, Zhou L, Tong Y, et al. Early transmission dynamics in Wuhan, China, of novel coronavirus-infected pneumonia. $N$ Engl J Med. (2020) 382:1199-207. doi: 10.1056/NEJMoa2001316

10. Eikenberry SE, Mancuso M, Iboi E, Phan T, Eikenberry K, Kuang Y, et al. To mask or not to mask: modeling the potential for face mask use by the general public to curtail the COVID-19 pandemic. Infect Dis Model. 5:293-308. doi: 10.1016/j.idm.2020.04.001

11. Modi PD, Nair G, Uppe A, Modi J, Tuppekar B, Gharpure AS, et al. COVID-19 awareness among healthcare students and professionals in mumbai metropolitan region: a questionnaire-based survey. Cureus. (2020) 12:e7514. doi: 10.7759/cureus.7514

12. Iboi EA, Richardson A, Ruffin R, Ingram D, Clark J, Hawkins J, et al. Impact of public health education program on the novel coronavirus outbreak in the United States. MedRxiv. (2021) 2021.01.18.21250047. doi: 10.1101/2021.01.18.21250047

13. Sedano-Chiroque FL, Rojas-Miliano C, Vela-Ruiz JM. Perspective on the primary prevention of COVID-19. Rev Facult Med Hum. (2020) 20:49097. doi: 10.25176/RFMH.v20i3.3031

14. World Health Organization. Advice on the Use of Masks in the Context of COVID-19: Interim Guidance. World Health Organization (2020). Available online at: https://apps.who.int/iris/handle/10665/331693 (accessed April 6 ${ }^{\text {th }}$, 2020). 
15. Das S, Sarkar S, Das A, Das S, Chakraborty P, Sarkar J. A comprehensive review of various categories of face masks resistant to covid-19. Clin Epidemiol Glob Health. (2021) 12:100835. doi: 10.1016/j.cegh.2021. 100835

16. Institute of Medicine. Reusability of Facemasks During an Influenza Pandemic: Facing the Flu. Washington, DC: The National Academies Press (2006). Available online at: https://doi.org/10.17226/11637

17. Ngonghala $\mathrm{CN}$, Iboi EA, Gumel AB. Could masks curtail the postlockdown resurgence of COVID-19 in the US? Math Biosci. (2020) 329:108452. doi: 10.1016/j.mbs.2020.108452

18. Worldometer. Worldometer, coronavirus, 2020 (2020). Available online at: https://www.worldometers.info/coronavirus/worldwide-graphs/\#total-cases (accessed April 2020).

19. Wang Y, Tian H, Zhang L, Zhang M, Guo D, Wu W, et al. Reduction of secondary transmission of SARS-CoV-2 in households by face mask use, disinfection and social distancing: a cohort study in Beijing, China. BMJ Global Health. (2020) 5:1-9. doi: 10.1136/bmjgh-2020002794

20. Ipsos. More People Say They're Wearing Masks to Protect Themselves From COVID-19 since March, 2020. (2020). Available online at: https://www.ipsos. $\mathrm{com} / \mathrm{en} / \mathrm{more}$-people-say-theyre-wearing-masks-protect-themselves-covid19-march (accessed 20 April, 2020).

21. Bricker, D. More people say they' re wearing masks to protect themselves from COVID-19 since March. There' $s$ been an increase in the number of people wearing masks. Game Changers (Ipsos). (2020) 2020:1-3.

22. Institute for Health Metrics and Evaluation. COVID-19 Maps of Mask Use. (2020). Available online at: https://covid19.healthdata.org/jordan?view= mask- use and tab=ma (accessed April 20, 2020).

23. Borg WR, Gall MD. Educational Research. 3rd ed. New York, NY: Longman (1993).

24. Fraenkel JR, Wallen NE. How to Design and Evaluate Research In Education. 6th ed. New York: McGraw-Hill (2005).
25. Quan F-S, Rubino I, Lee S-H, Koch B, Choi H-J. Universal and Reusable Virus Deactivation System for Respiratory Protection, Scientific Report. (2016) 7:1-10. doi: 10.1038/srep39956

26. Rengasamy S, Miller A, Eimer BC. Evaluation of the filtration performance of NIOSH-approved $\mathrm{n} 95$ filtering face-piece respirators by photometric and number-based test methods. J Occup Environ Hyg. (2011) 8:2330. doi: 10.1080/15459624.2010.515556

27. Bulletin TD. 3M TM Product Name Technical Data Bulletin Respiratory Protection for Airborne Exposures to Biohazards $3 M$ Personal Safety Division. (2020).

28. Tcharkhtchi A, Abbasnezhad N, Zarbini Seydani M, Zirak N, Farzaneh S, Shirinbayan M, et al. An overview of filtration efficiency through the masks: mechanisms of the aerosols penetration. Bioactive Mater. (2021) 6:10622. doi: 10.1016/j.bioactmat.2020.08.002

Conflict of Interest: The authors declare that the research was conducted in the absence of any commercial or financial relationships that could be construed as a potential conflict of interest.

Publisher's Note: All claims expressed in this article are solely those of the authors and do not necessarily represent those of their affiliated organizations, or those of the publisher, the editors and the reviewers. Any product that may be evaluated in this article, or claim that may be made by its manufacturer, is not guaranteed or endorsed by the publisher.

Copyright (C) 2022 Hudaib, Al-shawabkeh and Hudaib. This is an open-access article distributed under the terms of the Creative Commons Attribution License (CC BY). The use, distribution or reproduction in other forums is permitted, provided the original author(s) and the copyright owner(s) are credited and that the original publication in this journal is cited, in accordance with accepted academic practice. No use, distribution or reproduction is permitted which does not comply with these terms. 